\title{
Assessing Applied Pressure in Impedance Probe by Single-zone Force Sensing Resistors
}

\author{
By Pedro Bertemes Filho*
}

\begin{abstract}
Electrical impedance spectroscopy (EIS) is widely used for tissue characterization. Most EIS systems use tetrapolar electrode probes for taking the measurements, which are converted into the electrical properties of the material under study. One of the drawbacks is the applied pressure by the probe, resulting in a change in the measured impedance. The objective of this work is to develop a sensing mechanism for measuring the applied pressure by an electrode probe while measuring the impedance spectra of skin tissue. A system for both measuring the impedance spectra and the equivalent applied force by the probe was set. A measuring circuit of the force was developed by using single-zone force sensing resistors. Calibrations were made by using a sheet of hydrogel under different applied pressures in the frequency range $10 \mathrm{~Hz}$ to $1 \mathrm{MHz}$. Firm and soft pressure was applied in the skin of the distal forearm from a male volunteer of 46 years old. Results showed that the higher the applied pressure the higher the modulus of the impedance is, especially at lower frequencies. This might be important for better characterized tissue with different stiffness and elasticity.
\end{abstract}

Keywords: Applied Pressure, Electrical Bioimpedance, Hydrogel, Resistive Sensor.

\section{Introduction}

Electrical Impedance Spectroscopy (EIS) has been widely used as a noninvasive technique in many applications, such as in neuron-stimulation systems (Pouliquen et al., 2008; Basham et al., 2009; Sooksood et al., 2010), singleelectrode capacitive sensors (Chen et al., 2010), tomography (EIT) systems both for industrial and medical applications (Pease et al., 2008; Frounchi et al., 2009) and both normal and cancerous tissue characterization (Bertemes-Filho, 2002; Grimnes et al., 2008; Keshtkar et al., 2012; Aberg et al., 2003; Aberg et al., 2004).

The EIS technique is considered being a non-invasive, cheap, robust and easy-to-use technology for tissue characterization. Most EIS systems use a pair of electrodes for injecting a sinusoidal current into the material under study and another pair of electrodes for measuring the resulting potential. The injecting current is usually varied in a range of few Hertz to millions of Hertz. Then, an impedance spectrum is calculated and the electrical properties of the material under study are extracted by using an equivalent electrical model. Most measuring techniques use tetrapolar impedance probes, which are placed in contact with the material under study.

* Associate Professor, State University of Santa Catarina, Brazil. 
It has been showed that the electrode probe used to measure the impedance of tissue plays an important role for getting accurate readings and hence the measurements can be improved by changing the probe geometry (Jones et al., 2003; Gandhi et al., 2006; Bertemes Filho et al., 2003). Researches performed by Gonzalez-Correa et al (Gonzalez-Correa et al., 2005) showed that the resistivity of various tissues increase as the pressure of the measurement probe is increased. Similarly experiments on bladder tissue have shown that probe pressure has a significant effect on measured impedance (Keshtkar, 2008). It has been found that there is an optimal range of pressure to apply to particular tissues, with too little pressure not providing sufficiently reliable contact and too much pressure beginning to modify the tissue's properties (Keshtkar, 2011).

It is known that one of the most significant ways tissues become mechanically deformed is through compression. Therefore, it is very important to measure and control the pressure applied by the probe during measurements in order to get the right diagnosis (Jokhi et al., 2009). The commercial available impedance medical probes do not take into account the pressure effects when taking the measurements. A sheet of hydrogel was used as it mimics the tissue properties.

The main objective of this work is to develop a sensing mechanism for measuring the applied pressure by an electrode probe while measuring the impedance spectra in skin tissue.

\section{Methodology}

\section{A- System Setup}

The system used for measuring the impedance spectrum and the pressure applied by the electrode probe is shown in Figure 1. It consists of an impedance probe, an impedance analyzer and a data acquisition board.

Figure 1. Complete Set Up of the Measuring System

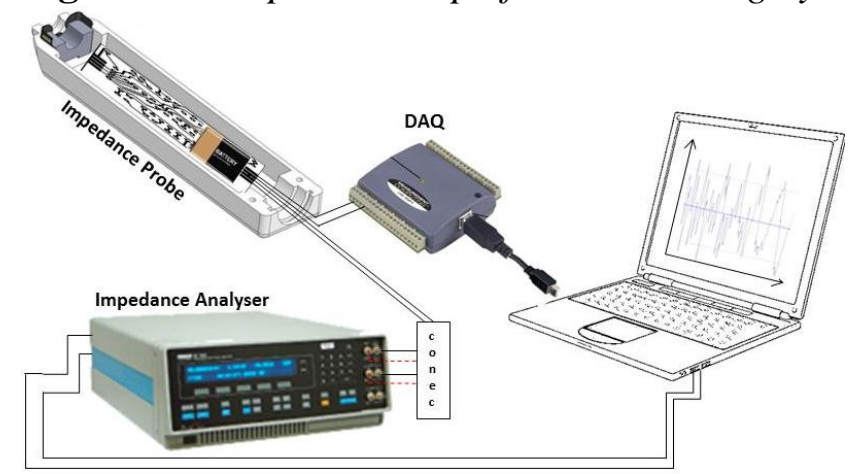

Source: Author.

4 single-zone force sensing resistors were inserted inside the probe case, as shown in the black drawings in Figure 2a. They are fixed and placed perpendicular to each other. The cross section areas of the resistors are in contact 
with the tube of the probe tip by means of a circular washer inside the probe case. The probe tip contains four gold electrodes of $1.0 \mathrm{~mm}$ equally spaced of $2.5 \mathrm{~mm}$ between centers and probe diameter is $4.5 \mathrm{~mm}$, as shown in Figure $2 \mathrm{~b}$.

Figure 2. Diagram of the Impedance Probe. (a) Internal View of the Probe Case Showing the Sensors. (b) Tube of the Probe, Showing the Electrode Array Geometry

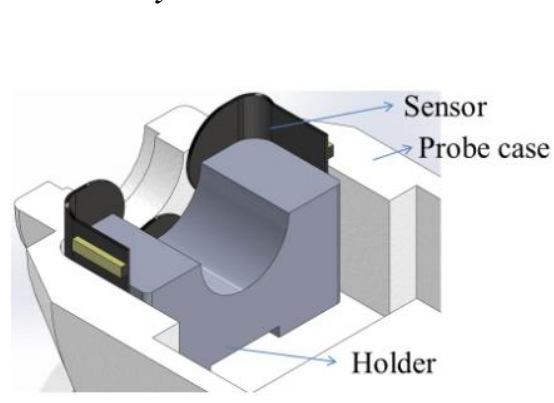

(a)

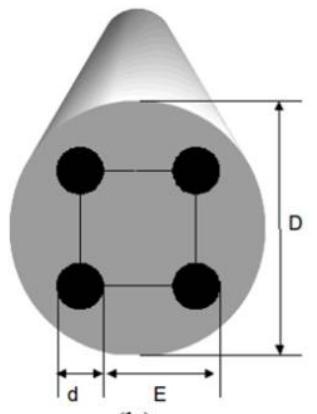

(b)

Source: Author.

An impedance/gain-phase analyzer from Solartron Analytical (model 1260A) was used for injecting the current, measuring the resulting potential and calculating the modulus and phase of the impedance spectra. The 4-terminal measurement configuration was used. A current sinusoidal signal of $1 \mathrm{mApp}$ (peak to peak) over the frequency range 0.1 to $1,000 \mathrm{kHz}$ was supplied by the current generator of the impedance analyzer with an accuracy of $0.1 \%$ and $0.1^{\circ}$. In practice, 37 discrete frequencies within the range were generated. The voltage was measured by two terminals and the output was registered in terms of the impedance modulus and phase. Data was transferred to the computer by using a GPIB-USB interface. It assured at least 10 complete cycles of signal acquisition, which are 10,000 samples for a signal of $1 \mathrm{kHz}$ at a sample rate of $10 \mathrm{MS} / \mathrm{s}$, and then the data was averaged for each discrete frequency in the range. The applied force of the probe was measured by a Data Acquisition (DAQ) board of 12 bits resolution (model USB-1208FS) from Measurement Computing. The resulting voltages were buffered (unit gain) in order to prevent load effects by the acquisition system. Data was scanned from one channel at a sample rate of 50 $\mathrm{kS} / \mathrm{s}$. The measurements were made 10 times in each sample for whole 33 discrete frequencies and then the data was averaged. Both pressure and impedance spectra were collected by a personal computer (notebook). Data were recorded and then analyzed. The material under study was a sheet of hydrogel of 40x40x1 mm.

\section{B-Pressure Sensing Circuit}

The circuit which converts the pressure applied on the sensors to an electrical signal is shown in Figure 3. It is based on the summing amplifier circuit using a very low offset voltage and noise level operational amplifier. The circuit is powered by a battery of 9 Volts. The voltage reference $\left(\mathrm{V}_{\text {ref }}\right)$ for the sensors is generated by the voltage reference AD580 from the Analog Devices. The gain of 
the circuit is controlled by the potentiometer $\mathrm{P}_{2}$ whereas $\mathrm{P}_{1}$ is used for nulling the output voltage $V_{O}$ when there is no pressure applied to the sensors.

Figure 3. Schematic Diagram of the Measuring Circuit

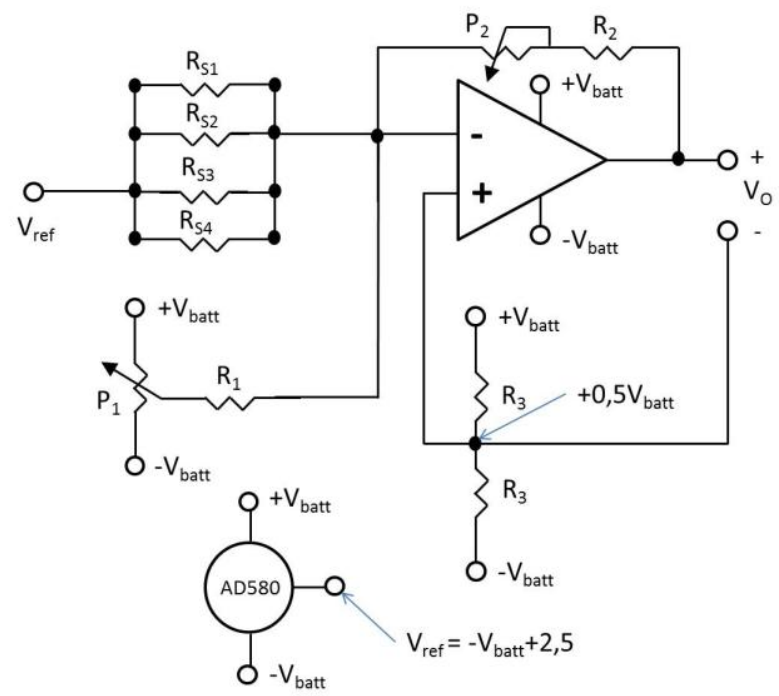

Source: Author.

\section{C - Experiment Setup}

Firstly, the impedance analyzer was calibrated by using a resistor of $50 \Omega$. In order to compensate for any loss of gain in the frequency range of $100 \mathrm{~Hz}$ to 1 $\mathrm{MHz}$, the impedance spectra of the resistor was measured.

Second, an experiment was set, in order to calibrate the measuring system for the applied forces by the probe, as shown in Figure 4. The probe was supported vertically while pressing down a sheet of hydrogel of 40x40x1 mm, which was placed on a circular acrylic disc of $115 \mathrm{~mm}$ diameter and a thickness of $3.5 \mathrm{~mm}$. The applied force into the hydrogel by the probe was indirectly measured by a digital scale from OHAUS manufacturer and the equivalent output voltage was also registered by the measuring system. The probe was manually pressured and kept still while measuring the equivalent weight. The weight was converted to force by using the gravity constant of $9.8 \mathrm{~m} / \mathrm{s}^{2}$ and measurements was made in the force range of 0 to $5 \mathrm{~N}$.

Finally, a commercially available sheet of hydrogel of 40x40x $1 \mathrm{~mm}$ was used for investigating the impedance change under two different applied pressures. 
Figure 4. Experimental Set-up for Calibrating the Probe and Measuring the Impedance Spectra of the Hydrogel

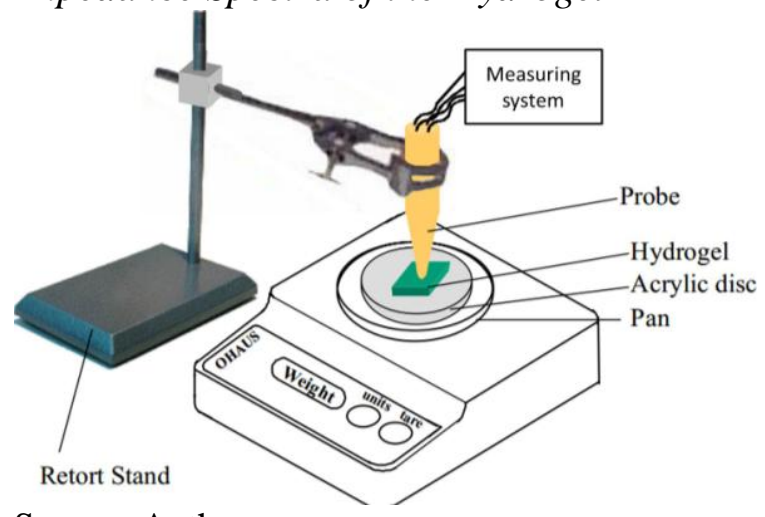

Source: Author.

\section{Results}

Figure 5 shows the output voltage measured by the circuit shown in Figure 3 as a function of the applied force by the probe. It can be seen that the output voltage of the circuit is almost linear in the applied force range of 0 to $4 \mathrm{~N}$, increasing by a rate of $1.86 \mathrm{~N} / \mathrm{V}$. It can also be observed that the offset level of the measuring circuit is 0.2 Volts and its output saturates at 2.3 Volts, which corresponds to $3.9 \mathrm{~N}$. Measurements were made by a digital voltmeter of $6^{1 / 2}$ digits resolution.

Figure 5. Curve Calibration for the Measuring Circuit Shown in Figure 3

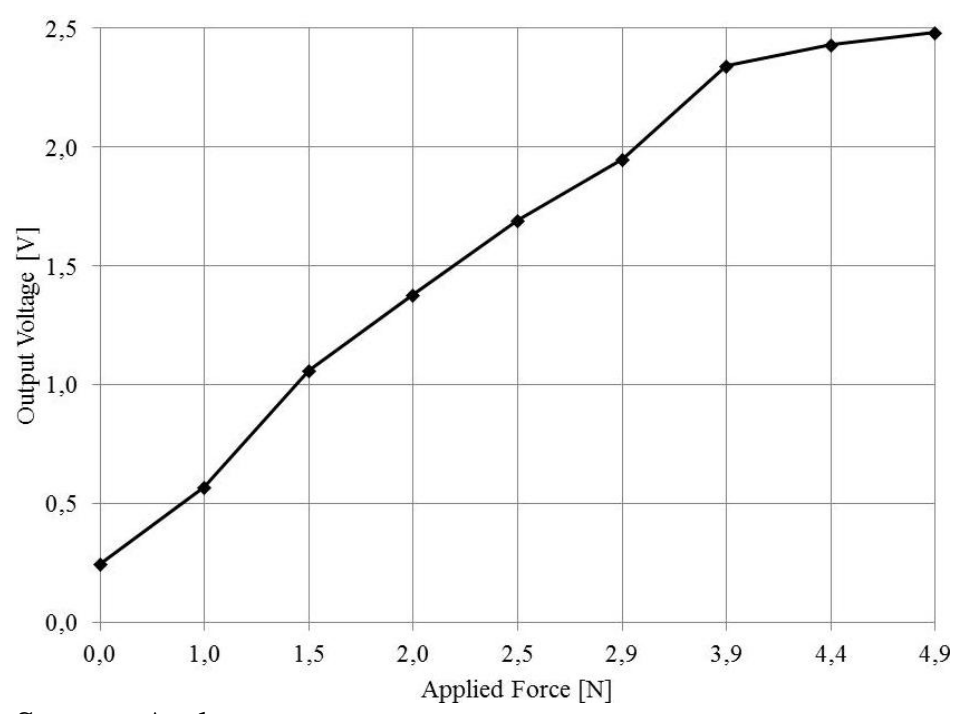

Source: Author.

Figure 6 shows the modulus of the impedance spectra in the frequency range $10 \mathrm{~Hz}$ to $1 \mathrm{MHz}$ measured at the surface of the hydrogel. The soft pressure (or force) was measured previously and it was $1 \mathrm{~N} \pm 5 \%$ whereas $4 \mathrm{~N} \pm 5 \%$ for the firm 
pressure. It can be seen that there is a quite significant difference in the impedance spectra at lower frequencies $(<100 \mathrm{~Hz})$. There impedance at $10 \mathrm{~Hz}$ for the soft pressure was $0.92 \mathrm{k} \Omega \pm 5 \%$ whereas $1.38 \mathrm{k} \Omega \pm 5 \%$ for the firm pressure. It can also be observed that there are almost no differences in the impedance spectra at high frequencies $(>100 \mathrm{~Hz})$.

Figure 6. Forearm Skin Impedance Spectra as a Function of Frequency

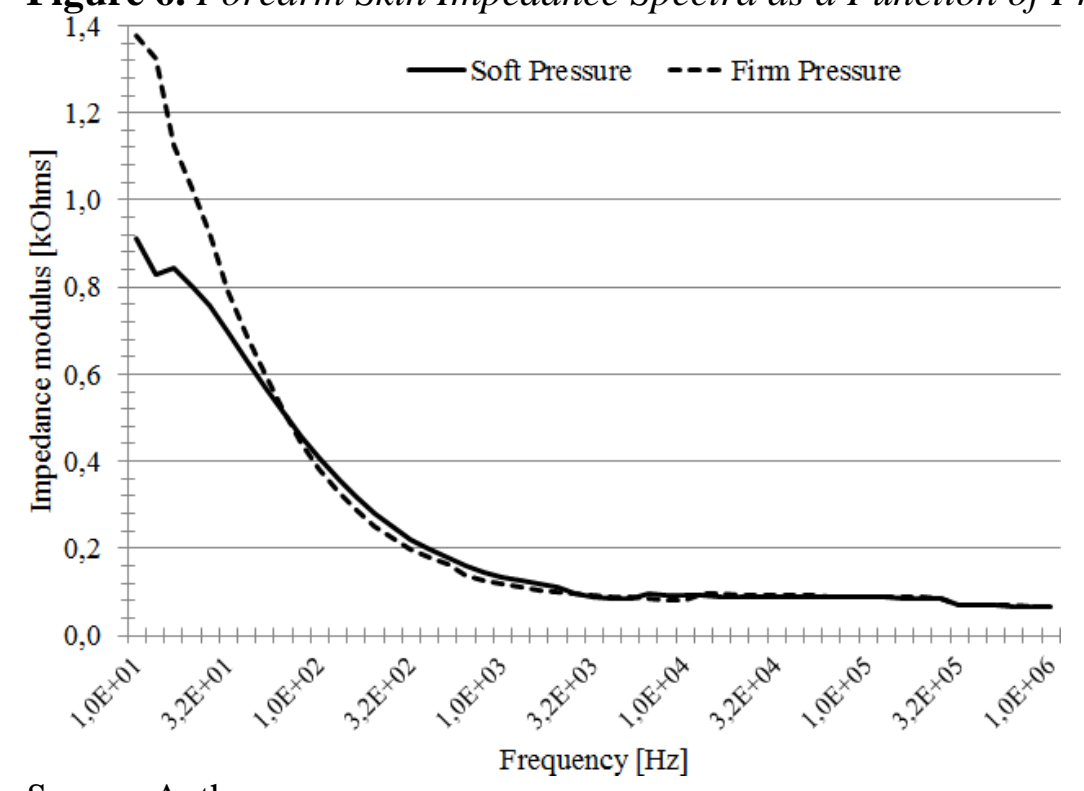

Source: Author.

\section{Discussion}

In order to investigate the performance of the single-zone forced sensing resistor, hydrogel was then used. The linearity of curve Force against Voltage was investigated for the proposed circuit. Firm and soft pressure was applied in the skin of the distal forearm from a male volunteer of 46 years old, then investigating the differences over the frequency range $100 \mathrm{~Hz}$ to $1 \mathrm{MHz}$. Further experiments with other types of gels and tissue in vitro measurements will be assessed in future works.

It was showed that the output voltage increases linearly with increasing the applied force by probe. This might be explained by the fact that a sheet of hydrogel for calibrating the circuit was used, which in turns, can be considered an isotropic material with a uniform distribution of conductivity within the material. A saturation of $3.9 \mathrm{~N}$ was observed, which can be increased by changing the noninverting input voltage of the operational amplifier. As a result, the applied force range might be increased to $10 \mathrm{~N}$ for a measured output voltage of $5 \mathrm{~V}$.

It has to be mentioned that the thicknesses of both hydrogel and acrylic discs were not taken into account and they might affect the electrical field distribution and hence the apparent impedance measured at the surface of the hydrogel by the probe.

Results have also showed that the impedance increases as increasing the 
applied force on the under study, which in this case was the skin of the distal part of the left forearm from a male volunteer of 46 years old. This might be explained by the fact that the amount of liquid is pushed away from the region under pressure. The liquids contain ions which are current carriers in terms of ionic conduction. Therefore, it is expected higher impedance at higher applied forces, especially at lower frequencies.

By the fact that the hydrogel is isotropic with a uniform distribution of conductivity, there were not stored of charges and hence no capacitive effects. As a result, this might not represent a good mimicking medium for calibration for such a type of probe prior skin measurements. Furthermore, the force sensing resistor might not be a proper sensor for measuring amorphous material, as it is hydrogel and tissue. On the other hand, a recent work using this type of sensor in tissue measurements reported feasible results (Zhou et al., 2016). Therefore, care should be taken for extending these results to other materials. Further analysis with biological materials need to be made in order to better validate the system.

\section{Conclusions}

It can be concluded that SZFS resistors can be used together with an impedance measuring system for better investigating the applied pressure effects in the impedance spectra of a biological material. These results might be important for better characterizing tissue with different stiffness and elasticity.

\section{Acknowledgments}

We thank the State University of Santa Catarina (UDESC) for the institutional support, the Science without Borders (CNPq) for the partial financial support [grant 237931/2012-5] and the FAPESC Research Santa Catarina State Agency (FAPESC) for the partial financial support [grant 2015TR127].

\section{References}

Aberg, P., Nicander, I., and Ollmar, S. Minimally inva-sive electrical impedance spectroscopy of skin exem-plified by skin cancer assessments. In Proceeding of the 25th Annual International Conference of the IEEE Engineering in Medicine and Biology Society (Cancun, Mexico, September 17-21 2008), 3211-3214. DOI= http://dx.doi.org/10.1109/IEMBS.2003.1280826.

Aberg, P., Nicander, I., Hansson, J., Geladi, P., Holmgren, U., and Ollmar, S. 2004. Skin cancer identification using multifrequency electrical impedance-a potential screening tool. IEEE Transactions on Biomedical Engineering. 51 (Dec. 2004), 2097-2102. DOI= http://dx.doi.org/10.1109/TBME.2004.836523.

Pouliquen, P., Vogelstein, J., and Etienne-Cummings, R. 2008. Practical considerations for the use of a Howland current source for neuron stimulation. In Proceedings of the IEEE Biomedical Circuits and Systems Conference (Baltimore, New York, November 20-22, 2008), New York, NY, 33-36. DOI= http://dx.doi.org/10.1109/ 
BIOCAS.2008.4696867.

Basham, E., Yang, Z., and Liu, W. 2009. Circuit and coil design for in-vitro magnetic neural stimulation systems. IEEE Transactions on Biomedical Circuits and Systems. 3,5 (Nov. 2009), 321-331. DOI= http://dx.doi.org/10.1109/TBCAS.2009.2024927.

Bertemes-Filho, P. 2002. Tissue Characterization Using an Impedance Spectroscopy Probe. Doctoral Thesis. University of Sheffield.

Bertemes-Filho, P., Brown, B. H., Smallwood, R. H., and Wilson, A. J. 2003. Stand-off electrode (SoE): a new method for improving the sensitivity distribution of a tetrapolar probe. Physiological Measurement. 24,2 (April 2003), 517-525. DOI= http://dx.doi.org/10.1088/0967-3334/24/2/362.

Chen, D. X., Deng, X., and Yang, W. Q. 2010. Comparison of three current sources for single-electrode capacitance measurement. Review of Scientific Instruments. 81,3 (Set. 2010), 1-3. DOI= http://dx.doi.org/10.1063/1.3367879.

Frounchi, J., Dehkhoda, F., and Zarifi M. H. 2009. A Low-Distortion Wideband Integrated Current Source for Tomography Applications. European Journal of Scientific Research. 27,1 (Dec. 2009), 56-65.

Gandhi, S. V., Walker, D. C., Brown, B. H., and Anumba, D. O. C. 2006. Comparison of human uterine cervical electrical impedance measurements derived using two tetrapolar probes of different sizes. BioMedical Engineering OnLine. 5,62 (Nov. 2006). DOI= http://dx.doi.org/10.1186/1475-925X-5-62.

Gonzalez-Correa, C. A., Brown, B. H., Smallwood, R. H., Walker, D. C., and Bardhan, K. D. 2005. Electrical bioimpedance readings increase with higher pressure applied to the measuring probe. Physiological Measurement. 30;26 (Mar. 2005), S39-S47. DOI= http://dx.doi.org/10.1088/0967-3334/26/2/004.

Grimnes, S., and Martinsen, O. G. 2008. Bioimpedance and Bioelectricity Basics. Elsevier Ltd.

Jokhi, R. P., Brown, B. H., and Anumba, D. O. C. 2009. The role of cervical Electrical Impedance Spectroscopy in the prediction of the course and outcome of induced labour. BMC Pregnancy and Childbirth. 9,40 (Mar. 2009). DOI= http://dx.doi.org/ 10.1186/1471-2393-9-40.

Jones, D. M., Smallwood, R. H., Hose, D. R., Brown,B. H., and Walker, D. C. 2003. Modelling of epithelial tissue impedance measured using three different designs of probe. Physiological Measurement. 24 (April 2003), 605-623. DOI= http://dx.doi. org/10.1088/0967-3334/24/2/369.

Keshtkar, A., and Keshtkar, A. 2008. The effect of applied pressure on the electrical impedance of the bladder tissue using small and large probes. Journal of Medical Engineering \& Technology. 32,6 (Dec. 2008), 505-11. DOI= http://dx.doi.org/ 10.1080/03091900701507456.

Keshtkar, A., Salehnia, A. Z., and Shokouhi, B. 2012. Bladder Cancer Detection Using Electrical Impedance Tech-nique (Tabriz Mark 1). Pathology Research International. 2012, 1 (Dec. 2012), 1-5. DOI= http://dx.doi.org/10.1155/2012/470101.

Keshtkar, A., and Keshtkar, A. 2011. Probe pressure optimisation in bioimpedance spectroscopy. International Journal of Medical Engineering and Informatics. 3,1 (Feb. 2011), 78-83. DOI= http://dx.doi.org/10.1504/IJMEI.2011.039078.

Pease, R. A. 2008. A Comprehensive Study of the Howland Current Pump. In Texas Instruments - Aplication Report. Available: at http://www.ti.com/lit/an/snoa474a/ snoa474a.pdf.

Sooksood, K., Stieglitz, T., and Ortmanns, M. 2010. An active approach for charge balancing in functional electrical stimulation. IEEE Transactions on Biomedical Circuits and Systems. 4,3 (Oct. 2010), 162-170. DOI= http://dx.doi.org/10.1109/TB CAS.2010.2040277. 
Zhou, Y., Ren, B., Li, B., Xu, J., Jin, Y., and Song, C. Changes in Small Intestine Tissue Compressed by a Linear Stapler Based on ColeY Model. Annals of Biomedical Engineering, (Jul. 2016). DOI: http://dx.doi.org/10.1007/s10439-016-1692-5. 
